\title{
Simple Prediction Formula for Proportion Installment Interest Rate in a Private Finance Initiative Project
}

\author{
Takanori Inoue ${ }^{1}$, Isamu Yoshitake ${ }^{2}$ \\ ${ }^{1}$ Sanyo Consultant Co., Ltd., Ube, Japan; ${ }^{2}$ Department of Civil and Environmental Engineering, Yamaguchi University, Ube, Japan. \\ Email: sp.inoue@sanyo-ct.co.jp
}

Received April 24 ${ }^{\text {th }}, 2013$; revised May 30 th $^{\text {th }}$ 2013; accepted July $5^{\text {th }}, 2013$

Copyright (C) 2013 Takanori Inoue, Isamu Yoshitake. This is an open access article distributed under the Creative Commons Attribution License, which permits unrestricted use, distribution, and reproduction in any medium, provided the original work is properly cited.

\begin{abstract}
Private Finance Initiative (PFI) projects aim to develop public facilities using private funds. Installment interest payments must be predominant in PFI project costs. The proportion of installment interest depends upon the business period, payment method, interest rate, and other factors. However, prediction of the installment interest is not simple. Cost simulation based on various assumptions has been required for planning PFI finance project. A simplified estimation formula for installment interest rate based on cost evaluations using wide range of comparable conditions is proposed in this paper. The applicability of the proposed formula is also discussed and verified. The proportion of installment interest of a PFI project can be estimated to sufficient accuracy using the proposed formula.
\end{abstract}

Keywords: Private Finance Initiative (PFI); Installment Interest Rate; Payment; Cost Simulation

\section{Introduction}

Private Finance Initiative (PFI) project finance generally includes installment interest payment during the business period in addition to design, construction, operation and maintenance (O\&M) costs. Prediction of the impact of installment interest rate cost employs simulations based on various assumptions, such as payment frequencies and so on. While several research papers discussing PFI projects have been published, few researches have focused on the effect of installment interest to the project finance.

Darinka and Matthias [1] reported risks faced by financial services providers in the United Kingdom and resolutions of risks based on the fact that most funds in PFI projects are borrowed from financial institutions. Darinka and Matthias [2] detailed the PFI funding process and financial capital using two case studies of recent PFI projects. Hellowell and Pollock [3] investigated the annual expenditure of existing PFI plans in Scotland, and presented the future cost prices arising from an increase in PFI. Kirk and Wall [4] investigated the accounting issue related to PFI projects on balance sheet, and they addressed substantial risk may be transferred to private sector. Hellowell and Vecchi [5] researched returns on investment and evaluated the operation of corporate financing methods for financial models used in 10 PFI projects of the National Health Service (NHS). Coulson [6] investigated constraints on business cost, tax, profitability, and financial investment institutions in PFI projects. Huntingdon and Fitzpatrick [7] verified that tax payers can benefit in the long term if service levels are held to predetermined standards.

Figure 1 shows the proportion of method of installment interest payment and payment frequency in $110 \mathrm{PFI}$ project cases planned in Japan. According to the results, equal principal and interest payment with four payments/ year are most common. Previous researches focused on the installment interest are scarce, though financial and risk management aspects of PFI projects are reported. To estimate the impact of installment interest rate, these factors should be considered. To estimate interest payments, cost simulations considering various conditions such as business period, payment method, interest payment method, and payment frequency are needed. It is not easy to estimate installment interest rate under various conditions via trial cost calculations, even in use of a computer. The variable detailed cost simulations mostly need additional planning cost. The leading planner of PFI project sometimes needs to estimate loans from the financial institution, including the interest payments, at site. A simplified prediction method by a calculator must be useful in such case. Additionally, the simplified method 


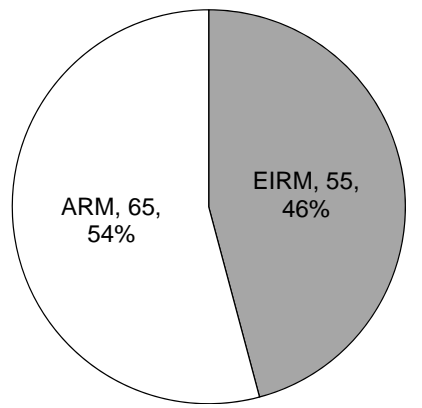

(a)

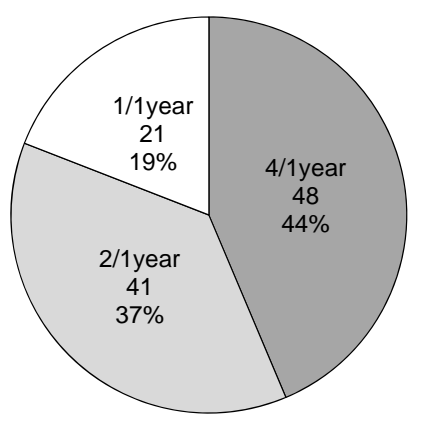

(b)

Figure 1. Proportion of method of installment interest payment and payment frequency. (a) Installment interest payment; (b) Payment frequency.

may contribute to the outline design of financial planning. The present study aims to propose a simplified practical formula predicting installment interest rate, which does not need cost simulations as before. The prediction formula is established considering wide range of design conditions, such as payment frequencies and so on. In addition, the applicability of the proposed formula is discussed by referring to actual PFI projects.

\section{Proposal of a Prediction Formula}

\subsection{Method of Calculating Installment Interest Rate}

Facilities cost, including installment interest, is provisionally calculated as "equivalent facilities cost" in this paper. Installment interest rate (installment interest/facilities cost) in different business periods is evaluated quantitatively. Also, the study examined relations between payment frequency and installment interest rate for each interest payment method. Uemura [8] presents formulae for estimating the equivalent facilities cost in equal installment repayment method (EIRM) and annuity repayment method (ARM).

[Equal installment repayment method: EIRM]

$$
y=s \times\left(\frac{\left(x \times x_{1}\right)+1}{2} \times \frac{r}{x_{1}}+1\right)
$$

[Annuity repayment method: ARM]

$$
y=\frac{s \times r / x_{1}}{1-\left(1+r / x_{1}\right)^{-n \times n 1}} \times x \times X_{1}
$$

where $y$ : equivalent facilities cost, $s$ : facilities cost, $x$ : business period (installment payment years), $x_{1}$ : number of annual installment payments, and $r$ : installment interest rate.

The installment interest cost can be obtained by subtracting facilities cost $(s)$ from the equivalent facilities $\operatorname{cost}(y)$. Herein, the proportion of installment interest $(E)$ is given by the following formula.

$$
E=\frac{y-s}{s}
$$

To examine impacts of installment interest rate, the provisional calculations with a wide range of payment frequency, business period, and interest rate are performed. The employed payment frequencies are $1 / 5,1 / 2$, $1 / 1,2 / 1,4 / 1,6 / 1,12 / 1$ (number of payments/year), and business periods are $5-100$ years. Also, the interest rates in the simulations are $1.0 \%, 3.0 \%, 6.0 \%$, and $10.0 \%$.

\subsection{Trend of Installment Interest Rate in a Wide Range of Design Conditions}

Figures $\mathbf{2}$ and $\mathbf{3}$ demonstrate the proportions installment interest in three kinds of payment frequencies, such as $1 / 5,1 / 1$, and 12/1 (times/year). It should be noted that the provisional calculations are based on an assumption of a facilities cost of 20 billion Yen.

Irrespective of the payment frequency, empirical relations of the proportion of installment interest rate $(E)$ and the project years $(x)$ can be expressed using a two dimension formula (Equation (4)). Similar relationships are also confirmed for other cases as well.

$$
E=a x^{2}+b x
$$

where $E$ : proportion of installment interest rate, $x$ : PFI project years (business period), and $a, b$ : coefficients. Table 1 gives regression coefficients $a, b$ in case of the

Table 1. Coefficients of a payment of 1/1 (time/year).

\begin{tabular}{cccc}
\hline & $\begin{array}{c}\text { Instalment interest } \\
\text { rate }(\%)\end{array}$ & Coef. $\boldsymbol{a}$ & Coef. $\boldsymbol{b}$ \\
\hline EIRM & 1.0 & 0.00000651 & 0.00520275 \\
& 3.0 & 0.00005589 & 0.01610416 \\
& 6.0 & 0.00014706 & 0.03598663 \\
& 10.0 & 0.00022226 & 0.06905554 \\
ARM & 1.0 & -0.00000158 & 0.00519493 \\
& 3.0 & -0.00000475 & 0.01558479 \\
& 6.0 & -0.00000951 & 0.03116957 \\
& 10.0 & -0.00001585 & 0.05194929 \\
\hline
\end{tabular}

EIRM: Equal installment repayment method, ARM: Annuity repayment method. 


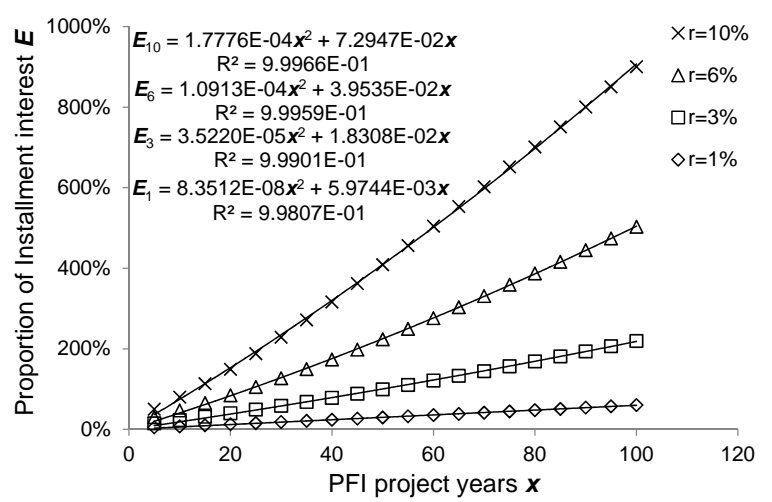

(a)

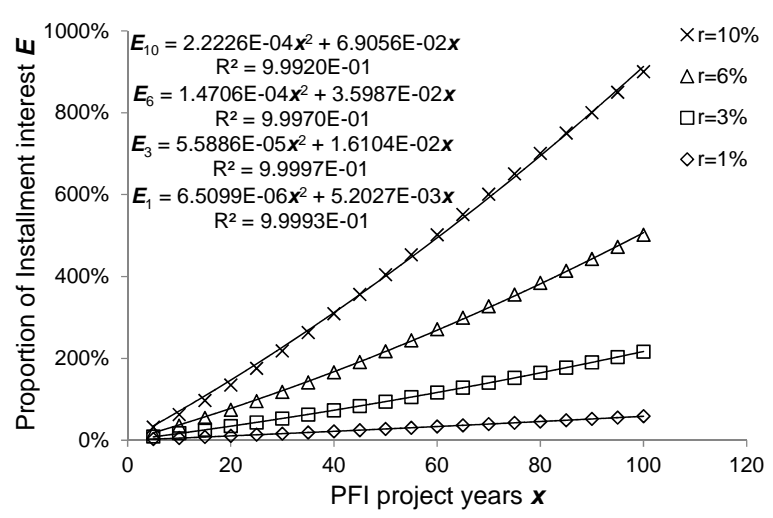

(b)

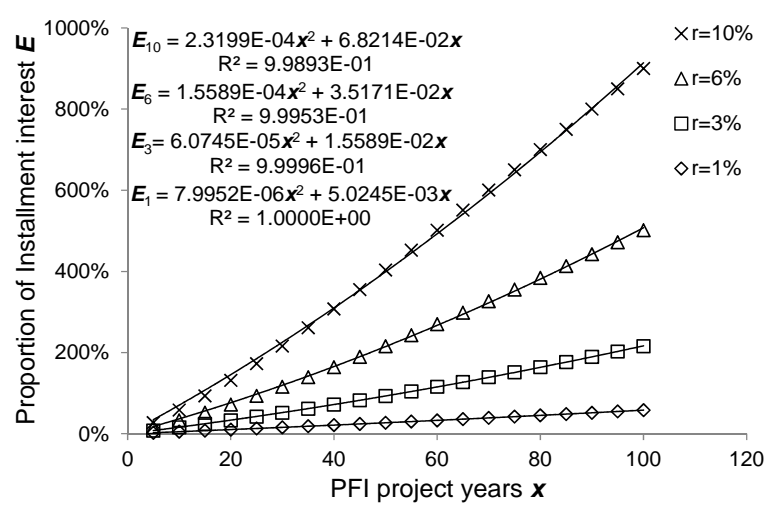

(c)

Figure 2. Cost simulations of equal installment repayment (EIRM). (a) 1/5; (b) 1/1; (c) 12/1.

payment frequency of 1/1 (number of payments/year). It should be noted that all coefficients were obtained from regression line, such as Figures 2 and 3. All coefficients $a$ for annuity repayment method (ARM) are negative, while the coefficients $a$ for the equal installment repayment method (EIRM) are positive.

\subsection{Proposal of a Simplified Prediction Formula}

Figures $\mathbf{4}$ and $\mathbf{5}$ present relations between installment interest rate $(r)$ and the coefficients ( $a, b$ in Equation (4)),

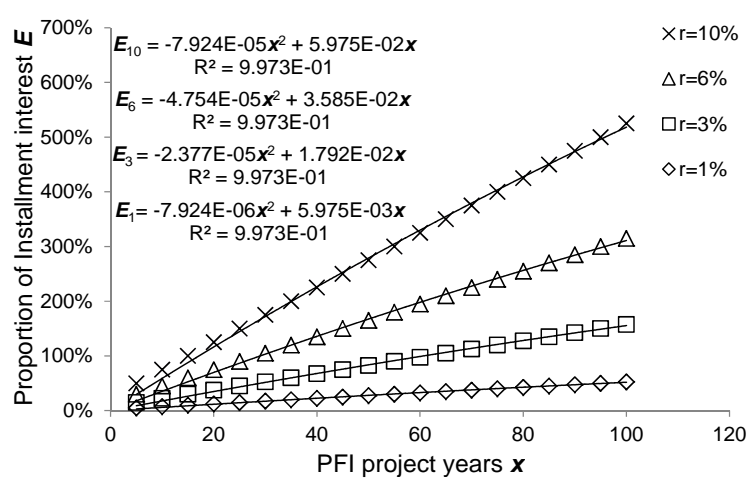

(a)

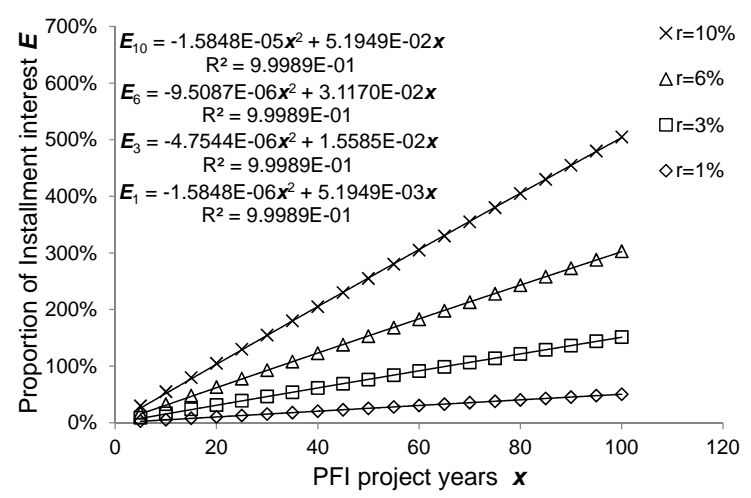

(b)

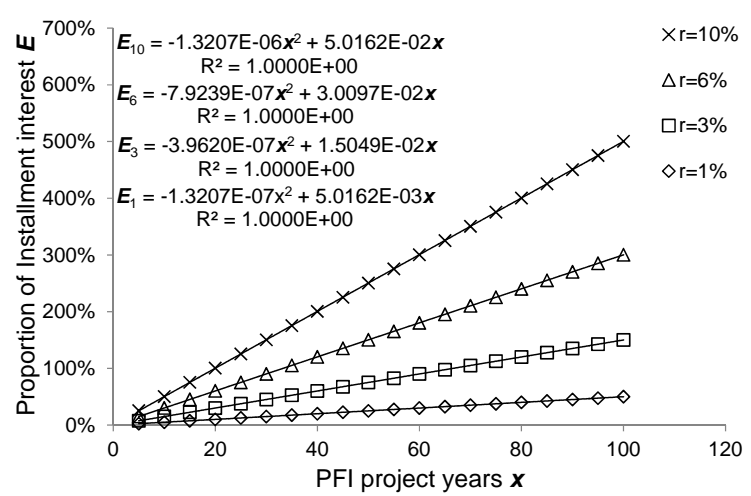

(c)

Figure 3. Cost simulations of annuity repayment (ARM). (a) 1/5; (b) $1 / 1$; (c) $12 / 1$.

respectively. The relations are almost linear, so the coefficients can be estimated using linear relations. It should be noted that the installment interest rates $(r)$ are shown in the $x$-axis by employing percentage. When calculating the coefficients, a decimal rate should be used.

Table 2 gives slopes of linear relation between interest rate and coefficients. A prediction formula for the proportion of installment interest rate $(E)$ is proposed herein.

$$
\begin{aligned}
E & =a(r) \cdot x^{2}+b(r) \cdot x \\
& =k_{a} \cdot r \cdot x^{2}+k_{b} \cdot r \cdot x \\
& =\left(k_{a} \cdot x+k_{b}\right) \cdot r \cdot x
\end{aligned}
$$




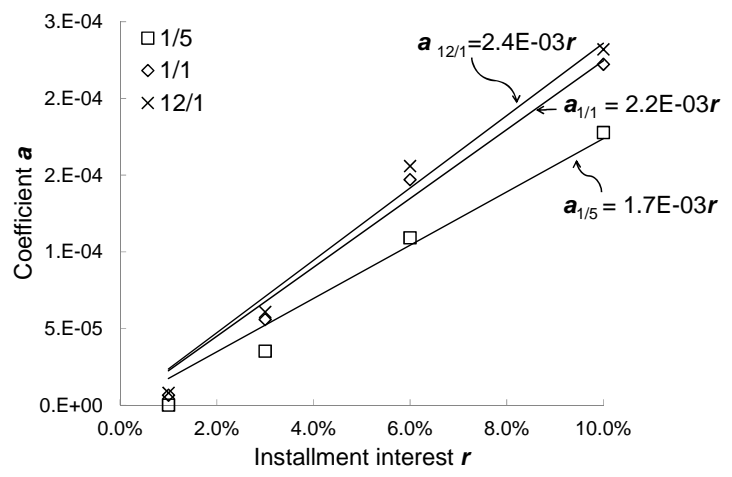

(a)

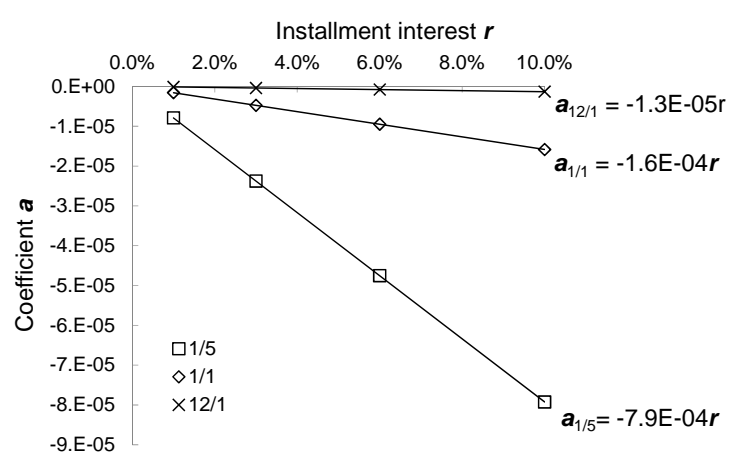

(b)

Figure 4. Relations between installment interest rate $(r)$ and the coefficients (a). (a) EIRM; (b) ARM.

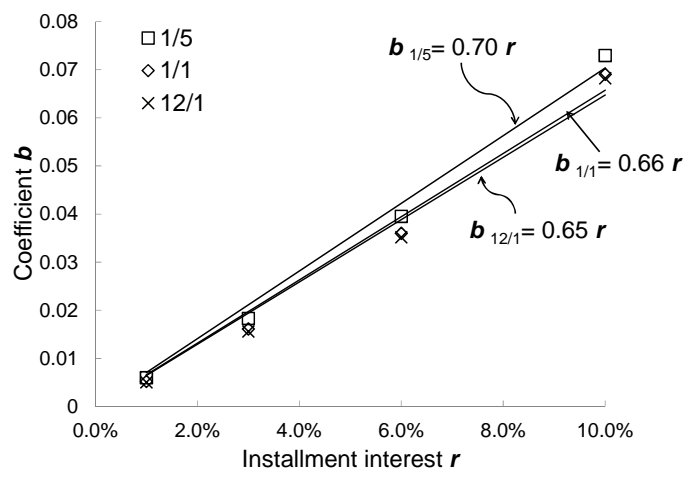

(a)

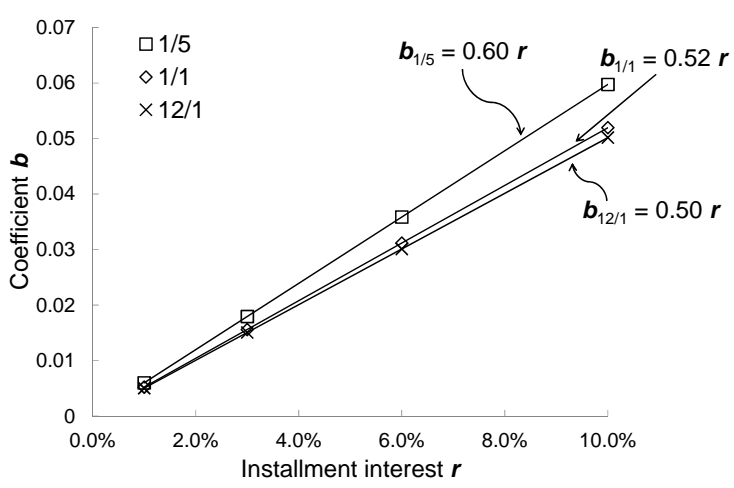

(b)

Figure 5. Relations between installment interest rate $(r)$ and the coefficients (b). (a) EIRM; (b) ARM.
Table 2. Slopes of linear relations (a-r, b-r).

\begin{tabular}{ccccc}
\hline $\begin{array}{c}\text { Payment } \\
\text { frequency } \\
\text { (time/year) }\end{array}$ & \multicolumn{2}{c}{ EIRM } & \multicolumn{2}{c}{ ARM } \\
\cline { 2 - 5 } $\boldsymbol{k}_{\boldsymbol{a}}$ & $\boldsymbol{k}_{\boldsymbol{b}}$ & $\boldsymbol{k}_{\boldsymbol{a}}$ & $\boldsymbol{k}_{\boldsymbol{b}}$ \\
\hline $1 / 5$ & $1.7 \times 10^{-3}$ & 0.70 & $-7.9 \times 10^{-4}$ & 0.60 \\
$1 / 4$ & $1.8 \times 10^{-3}$ & 0.69 & $-6.2 \times 10^{-4}$ & 0.58 \\
$1 / 3$ & $1.9 \times 10^{-3}$ & 0.68 & $-4.9 \times 10^{-4}$ & 0.56 \\
$1 / 2$ & $2.1 \times 10^{-3}$ & 0.65 & $-3.1 \times 10^{-4}$ & 0.54 \\
$1 / 1$ & $2.2 \times 10^{-3}$ & 0.66 & $-1.6 \times 10^{-4}$ & 0.52 \\
$2 / 1$ & $2.2 \times 10^{-3}$ & 0.66 & $-8.0 \times 10^{-5}$ & 0.51 \\
$3 / 1$ & $2.3 \times 10^{-3}$ & 0.65 & $-5.1 \times 10^{-5}$ & 0.51 \\
$4 / 1$ & $2.3 \times 10^{-3}$ & 0.65 & $-3.8 \times 10^{-5}$ & 0.50 \\
$6 / 1$ & $2.3 \times 10^{-3}$ & 0.65 & $-3.1 \times 10^{-5}$ & 0.50 \\
$12 / 1$ & $2.4 \times 10^{-3}$ & 0.65 & $-1.3 \times 10^{-5}$ & 0.50 \\
\hline Al & &
\end{tabular}

*All coefficients $\left(k_{a}, k_{b}\right)$ were obtained from the regression line as well as coefficients $(a, b)$.

where $k_{a}, k_{b}$ are coefficients given in Table 2 .

\section{Applicability of the Proposed Formula}

The applicability of the proposed formula (Equation (5)) is verified. Six PFI projects in Japan are used for the verification. The PFI projects were public apartments (Case 1, 4, 5, 6), an elementary school (Case 2), and a public supply center for school meals (Case 3). Table 3 gives fundamental information for the projects, such as business periods, payment methods and installment interest rates. Table 3 also presents the actual/predicted proportion installment interest rates of each project. By employing the proposed formula, the proportions were estimated with an accuracy of $1.03-1.19$. The accuracy of the proposed simple method may be appropriate for financial outline design of PFI projects. The results imply that the proposed formula can be recommended as a simple estimation, and that it can contribute to planning and designing of PFI finance.

\section{Summary and Conclusions}

As installment interest payments may prove the dominant factor in overall PFI project costs, the present study aimed to examine their impact in overall cost. A simplified formula estimating the proportion of installment interest payment was proposed using cost simulations. The conclusions of the study are as follows:

- Based on the provisional calculations conducted under a wide range of design conditions, proportion of installment interest payment $(E)$ can be expressed with a two-dimensional formula of business period $(x)$ irrespective of the payment frequency. 
Table 3. Verification of applicability of the proposed formula.

\begin{tabular}{|c|c|c|c|c|c|c|}
\hline & Case 1 & Case 2 & Case 3 & Case 4 & Case 5 & Case 6 \\
\hline i. Business period (years) & 27 & 20 & 15 & 7 & 7 & 7 \\
\hline ii. EIRM or ARM & EIRM & EIRM & EIRM & ARM & ARM & ARM \\
\hline iii. Paying method (time/year) & $2 / 1$ & $1 / 1$ & $4 / 1$ & $1 / 1$ & $1 / 1$ & $1 / 1$ \\
\hline iv. I.I.R. ${ }^{a}(\%)$ & 1.89 & 1.94 & 2.70 & 1.90 & 1.81 & 1.67 \\
\hline v. Facilities cost ( $\left.10^{6} \mathrm{JPY}\right)$ & 1588 & 2060 & 2301 & 1900 & 2820 & 6396 \\
\hline vi. Cost of I.I.R. ${ }^{a}\left(10^{6} \mathrm{JPY}\right)$ & 492 & 381 & 470 & 126 & 179 & 348 \\
\hline vii. Proportion of I.I.R. ${ }^{a}(\%)$ & 30.97 & 18.51 & 20.42 & 6.65 & 6.34 & 5.44 \\
\hline $\begin{array}{l}\text { viii. Prediction by the formula given in } \\
\text { Equation }(5)(\%)\end{array}$ & 36.77 & 20.08 & 20.96 & 6.90 & 6.58 & 6.07 \\
\hline ix. Ratio (viii/vii) & 1.19 & 1.09 & 1.03 & 1.04 & 1.04 & 1.12 \\
\hline
\end{tabular}

${ }^{\mathrm{a}}$ Installment interest rate.

- The proposed formula has appropriate estimation accuracy for installment interest rate for both the annuity repayment method and the equal installment repayment method. To confirm the practical use, applicability of the formula should be discussed using more PFI finance projects in the future research.

\section{REFERENCES}

[1] A. Darinka and B. Matthias, "The UK Financial Sector and Risk Management in PFI Projects: A Survey," Public Money \& Management, Vol. 23, No. 3, 2003, pp. 195202. doi:10.1111/1467-9302.00368

[2] A. Darinka and B. Matthias, "Crucial Silences: When Accountability Met PFI and Finance Capital," Critical Perspectives on Accounting, Vol. 21, No. 1, 2010, pp. 113. doi:10.1016/j.cpa.2008.09.009

[3] M. Hellowell and A. M. Pollock, "New Development: The PFI: Scotland's Plan for Expansion and Its Implications," Public Money \& Management, Vol. 27, No. 5, 2007, pp. 351-354. doi:10.1111/j.1467-9302.2007.00607.x
[4] R. J. Kirk and A. P. Wall, "Substance, Form and PFI Contracts," Public Money \& Management, Vol. 21, No. 3, 2001, pp. 41-46. doi:10.1111/1467-9302.00273

[5] M. Hellowell and V. Vecchi, "An Evaluation of the Projected Returns to Investors on 10 PFI Projects Commissioned by the National Health Service," Financial Accountability and Management, Vol. 28, No. 1, 2012, pp. 77-100. doi:10.1111/j.1468-0408.2011.00537.x

[6] A. Coulson, "Value for Money in PFI Proposals: A Commentary on the UK Treasury Guidelines for Public Sector Comparators," Public Administration, Vol. 86, No. 2, 2008, pp. 483-498. doi:10.1111/j.1467-9299.2008.00729.x

[7] J. Huntingdon and B. Fitzpatrick, "Deriving Value from PFI \& PPP through Effective Asset Valuation and Management in the Public Sector," Asset Management Conference, 2011, pp. 1-6.

[8] T. Uemura, "Teach It from Beginning; Is an Interest Rate/ an Interest Rate Classroom," Kanki Publication, 2004 (in Japanese). 